\title{
A New Analysis Tool Assessment for Rotordynamic Modeling of Gas Foil Bearings
}

Samuel A. Howard

Glenn Research Center, Cleveland, Ohio

Luis San Andres

Texas A\&M University, College Station, Texas 


\section{NASA STI Program . . . in Profile}

Since its founding, NASA has been dedicated to the advancement of aeronautics and space science. The NASA Scientific and Technical Information (STI) program plays a key part in helping NASA maintain this important role.

The NASA STI Program operates under the auspices of the Agency Chief Information Officer. It collects, organizes, provides for archiving, and disseminates NASA's STI. The NASA STI program provides access to the NASA Aeronautics and Space Database and its public interface, the NASA Technical Reports Server, thus providing one of the largest collections of aeronautical and space science STI in the world. Results are published in both non-NASA channels and by NASA in the NASA STI Report Series, which includes the following report types:

- TECHNICAL PUBLICATION. Reports of completed research or a major significant phase of research that present the results of NASA programs and include extensive data or theoretical analysis. Includes compilations of significant scientific and technical data and information deemed to be of continuing reference value. NASA counterpart of peer-reviewed formal professional papers but has less stringent limitations on manuscript length and extent of graphic presentations.

- TECHNICAL MEMORANDUM. Scientific and technical findings that are preliminary or of specialized interest, e.g., quick release reports, working papers, and bibliographies that contain minimal annotation. Does not contain extensive analysis.

- CONTRACTOR REPORT. Scientific and technical findings by NASA-sponsored contractors and grantees.
- CONFERENCE PUBLICATION. Collected papers from scientific and technical conferences, symposia, seminars, or other meetings sponsored or cosponsored by NASA.

- SPECIAL PUBLICATION. Scientific, technical, or historical information from NASA programs, projects, and missions, often concerned with subjects having substantial public interest.

- TECHNICAL TRANSLATION. Englishlanguage translations of foreign scientific and technical material pertinent to NASA's mission.

Specialized services also include creating custom thesauri, building customized databases, organizing and publishing research results.

For more information about the NASA STI program, see the following:

- Access the NASA STI program home page at http://www.sti.nasa.gov

- E-mail your question via the Internet to help@ sti.nasa.gov

- Fax your question to the NASA STI Help Desk at $443-757-5803$

- Telephone the NASA STI Help Desk at 443-757-5802

- Write to: NASA Center for AeroSpace Information (CASI) 7115 Standard Drive Hanover, MD 21076-1320 


\section{A New Analysis Tool Assessment for Rotordynamic Modeling of Gas Foil Bearings}

\section{Samuel A. Howard}

Glenn Research Center, Cleveland, Ohio

Luis San Andres

Texas A\&M University, College Station, Texas

Prepared for the

Turbo Expo 2010

sponsored by the American Society of Mechanical Engineers (ASME)

Glasgow, Scotland, United Kingdom, June 14-18, 2010

National Aeronautics and

Space Administration

Glenn Research Center

Cleveland, Ohio 44135 
This report contains preliminary findings, subject to revision as analysis proceeds.

Trade names and trademarks are used in this report for identification only. Their usage does not constitute an official endorsement, either expressed or implied, by the National Aeronautics and Space Administration.

Level of Review: This material has been technically reviewed by technical management.

Available from

NASA Center for Aerospace Information 7115 Standard Drive

Hanover, MD 21076-1320
National Technical Information Service 5301 Shawnee Road Alexandria, VA 22312

Available electronically at http://gltrs.grc.nasa.gov 


\title{
A New Analysis Tool Assessment for Rotordynamic Modeling of Gas Foil Bearings
}

\author{
Samuel A. Howard \\ National Aeronautics and Space Administration \\ Glenn Research Center \\ Cleveland, Ohio 44135 \\ Luis San Andres \\ Texas A\&M University \\ College Station, Texas 77843
}

\begin{abstract}
Gas foil bearings offer several advantages over traditional bearing types that make them attractive for use in high-speed turbomachinery. They can operate at very high temperatures, require no lubrication supply (oil pumps, seals, etc.), exhibit very long life with no maintenance, and once operating airborne, have very low power loss. The use of gas foil bearings in high-speed turbomachinery has been accelerating in recent years, although the pace has been slow. One of the contributing factors to the slow growth has been a lack of analysis tools, benchmarked to measurements, to predict gas foil bearing behavior in rotating machinery. To address this shortcoming, NASA Glenn Research Center (GRC) has supported the development of analytical tools to predict gas foil bearing performance. One of the codes has the capability to predict rotordynamic coefficients, power loss, film thickness, structural deformation, and more. The current paper presents an assessment of the predictive capability of the code, named XLGFBTH (Texas A\&M University). A test rig at GRC is used as a simulated case study to compare rotordynamic analysis using output from the code to actual rotor response as measured in the test rig. The test rig rotor is supported on two gas foil journal bearings manufactured at GRC, with all pertinent geometry disclosed. The resulting comparison shows that the rotordynamic coefficients calculated using XLGFBTH represent the dynamics of the system reasonably well, especially as they pertain to predicting critical speeds.
\end{abstract}

\section{Introduction}

Small, high-speed, lightly-loaded turbomachinery offers a class of applications with demands well-matched to the performance capabilities of Gas Foil Bearings. Examples of applications of commercial and industrial interest include: engines for turboshaft propulsion, general aviation propulsion, regional jet propulsion, turbo-generators, turbo-compressors, turbo-pumps, blowers, motors, etc. Successful machines, such as micro turbine generators, utilizing gas foil bearing technology demonstrate that the technology is feasible for turbomachinery of this size class. Design of such systems, however, is currently more of an art than a science because of a lack of accurate computational design tools and procedures. There have been some efforts to develop the tools and procedures necessary to design using minimal hardware and experimentation iterations. Several computational tools for predicting performance and rotordynamic coefficients to enable detailed design have emerged lately. This emergence exposes another deficiency in the lack of experimental data available to validate models and predictive capabilities. This paper seeks to assess the capabilities of a recently developed foil journal bearing analysis tool by comparison of predicted to measured response to accurately model the dynamics of a rotor bearing system.

\section{Nomenclature}

E Bearing eccentricity

$\mathrm{C}_{\mathrm{xx}} \quad$ Damping coefficient (subscript denotes direction)

$\mathrm{K}_{\mathrm{xx}} \quad$ Stiffness coefficient (subscript denotes direction)

$\mathrm{P} \quad$ Predicted pressure

$\mathrm{P}_{\mathrm{a}} \quad$ Ambient pressure

X Horizontal coordinate

Y Vertical coordinate

$\alpha \quad$ Eccentricity angle

$\omega \quad$ Rotational velocity

\section{Background}

A typical bump-type journal foil bearing is shown in Figure 1. The basic design consists of a compliant "foil" structure acting as the bearing surface inside a rigid shell. A hydrodynamic air film is generated in the space between the smooth top surface of the foil structure and a rotating shaft/journal inserted in the bearing. The compliant structure allows for deformation of the bearing to accommodate shaft centrifugal growth, thermal growth, misalignment, dynamic shaft motion, etc. The compliant structure also yields bearing performance characteristics that can be tailored to a specific application to some extent. Parametric design variations can result in more or less stiffness and damping, for example, to better match the demands of a particular application. The appeal of gas foil bearings lies in their ability to operate in the extreme environments of high temperature and high speed 


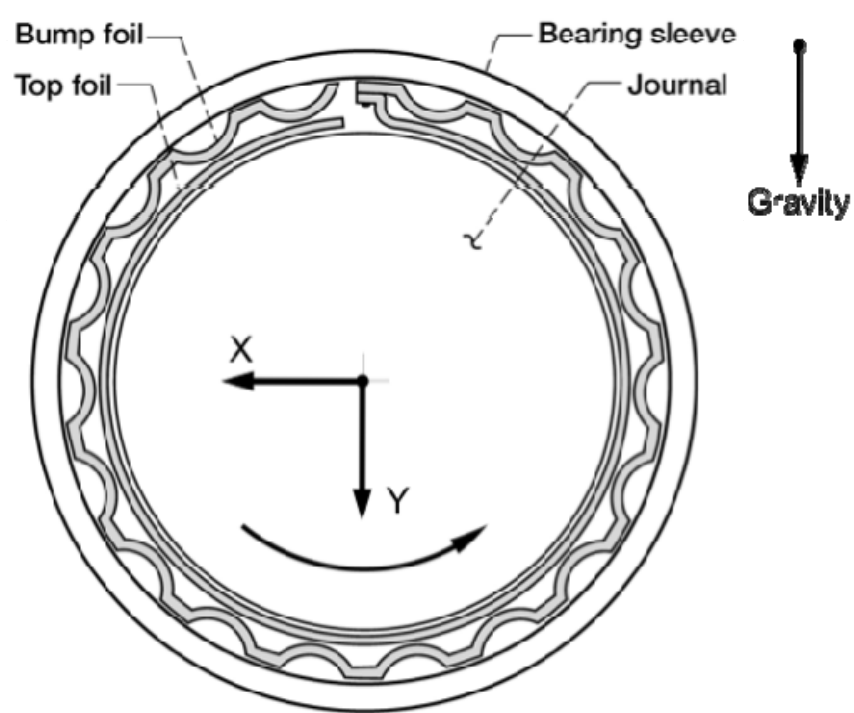

Figure 1.-Typical bump-type foil journal bearing cross-section.

while eliminating the need for a lubricant supply and potentially exhibiting long life cycles with low maintenance and low power loss. Therefore, there is a strong desire to develop the ability to accurately model the bearings' static and dynamic performance characteristics. There has been a fair amount of work done to characterize the structural stiffness and damping properties of the compliant structure in gas foil bearings. These analyses focus only on the mechanical properties of the bump foil strips and top foil, without the hydrodynamic film contribution due to journal rotation. The motivation for these studies comes from the fact that the overall gas foil bearing stiffness and damping coefficients are a series combination of the support structure (bump foil) stiffness and the hydrodynamic (gas film) stiffness. Therefore, these studies have the potential to elucidate some of the underlying physical behavior of the overall bearing. Additionally, various models for the bump foil structure can be analyzed and compared to experimental results without the added complexity of the hydrodynamics in order to screen appropriate structural models for integration into a complete analysis tool.

$\mathrm{Ku}$ and Heshmat (Refs. 1 and 2) were among the first to report such work. Their analysis and experimentation indicate that the distance between bumps in the support structure, or bump pitch, is an important parameter in dictating the structural stiffness. The number of bumps, types of surface coatings, and the presence of lubricant also influenced stiffness and damping, but to a lesser extent. A few years later, $\mathrm{Ku}$ and Heshmat (Ref. 3) extended their experiments to include applied load. Higher static loads were found to increase the structural stiffness of the bump foil strips. A frequency dependence was also identified.

Recently, there has been more interest in this topic, Rubio and San Andres (Ref. 4) conducted experiments wherein a bearing was subjected to increasing static loads while the displacement was monitored. These so-called load-deflection curves show a dependence of the structural stiffness on load magnitude, amplitude of motion, dry-friction coefficient, radial clearance/preload, and bump geometry. Also present was hysteresis in the load deflection curve demonstrating that frictional forces do, in fact, provide significant mechanical energy dissipation or damping in oscillatory bearing motions.

Le Lez, et al. (Ref. 5) advance a more detailed analytical study of support structure behavior by conducting a finite element analysis of the bump foil, including bump interactions with each other. Their findings again indicate that applied load and friction coefficient are important parameters, and to a lesser extent frequency of oscillation. They also point out that stick-slip occurs in foil bearing support structures leading to the hysteretic frictional damping observed by others.

Lee, et al. (Ref. 6) studied the structural stiffness and damping coefficients using finite element analysis, as well. In addition, they included the effect of temperature. As with the others, they found bump geometry, including bump pitch/width and height, to affect stiffness. The effect of increased temperature was to decrease both stiffness and damping of the bump support structure due to a loss of material strength at higher temperature.

All of the previous works serve to enable future advanced analysis tools for gas foil bearings including the hydrodynamic gas film. A brief summary of efforts to model foil bearings with coupled hydrodynamics and structural analysis follows: Heshmat, et al. (Refs. 7 and 8) present the first detailed analysis of gas foil bearings. Their model is among the simplest of models in the literature, applying a compliance parameter to the sub-foil structure. The compliance parameter, $\alpha$, is an analytic expression of the inverse of the bump foil stiffness based upon material and geometry. The foil deformation and fluid pressure are coupled through the film thickness relationship. In this manner, the stiffness of the bump foil structure is modeled as a continuous elastic foundation with local stiffness independent of global foil deflections. In other words, deflections in one location do not affect deflections in other locations. Dimensionless results of bearing performance characteristics are reported, but insufficient geometry information is provided to garner useful design data from the results.

Iordanoff (Ref. 9) used a simple model with a linear compliance distribution in thrust bearings to solve for load and power loss. He developed a methodology to determine the best geometry for a given operating point and for a given operating range. He used his model to design a thrust bearing that demonstrated roughly a five-fold improvement in load capacity over previous designs.

Heshmat, et al. (Ref. 10) used a commercial finite element code to model the structural bump foil supports coupled with a finite difference model of the gas film to predict steady state load performance of gas foil thrust bearings. Good agreement is shown between predictions and measurements for static load capacity. This method potentially can be used to model steady state performance, but its usefulness is limited due to 
numerical inefficiency and convergence issues for dynamic analyses.

Bruckner (Ref. 11) analyzed foil thrust bearings using a biharmonic plate equation to model the top foil with a stiffness function representing the bump foil support structure. He also included a thermal analysis to determine the temperature field in the gas film. The thermal deformations of the foil structure are not included in this model. The structural equation and the Reynolds equation for the hydrodynamics were solved using a central differencing scheme, while the energy equation was solved using a type of shooting function for the temperature field. All three solutions are iterated upon until a converged solution is found. The results for predicted foil deflections show high spots in locations similar to wear scar patterns found in practice, and the temperature predictions are reasonably close to indicate that including thermal effects is important when modeling gas foil bearings. This is a steady state thrust bearing analysis, however, the methodology could be extended to predict dynamic coefficients of journal bearings, although it would likely be quite slow due to the multiple levels of iteration involved. It is important in that it shows it is necessary to include thermal effects in the modeling of gas foil bearings.

Peng and Carpino (Refs. 12 and 13) use a finite difference solution technique to predict gas foil journal bearing stiffness and damping. The model uses an equivalent stiffness for the structure coupled with the Reynolds' equation for the gas film. To model the frictional damping mechanism between the foils and between the foils and housing, they use a viscous damping model with the same energy dissipation as the dry friction mechanism.

Carpino et al. (Refs. 14 and 15) developed a more sophisticated analysis using a finite element formulation. The gas film and structure are coupled via the pressure field and solved iteratively. In this model, the bending and membrane effects of the top foil are included as well as the deformations of the sub-foil structure.

Carpino and Talmadge (Refs. 16 and 17) have developed a quite detailed model for foil journal bearings. The bending and membrane effects of the top foil are again included and are coupled through moment, tension, curvature, and strain equations. The model uses a single cylindrical shell finite element to represent both the gas film and the structural model. The top foil sag between bumps, and individual bump behavior are not included. An interesting result of this work is a prediction that damping decreases with increased friction coefficient due to the bump foil locking up above certain friction levels.

Lee, et al. (Ref. 18) couple an elastic foundation model for the foil structure to the Reynolds' equation including the effects of slip flow (high Knudsen number). The results indicate that for much of the operating regime, slip flow is negligible. However, at high load, low speed, and high temperature conditions, when the film thickness is small compared to the mean free path for air, slip flow can have significant influence on the load capacity and dynamic bearing coefficients.

Peng and Khonsari advance isothermal (Ref. 19) and thermohydrodynamic (Ref. 20) analyses of gas foil journal bearings. In the isothermal model, the authors use a model similar to Heshmat's (Refs. 7 and 8) to predict steady-state operating characteristics. They compare the load carrying capacity and stability to that of rigid gas bearings, and report that compliant gas bearings offer higher load capacity and better stability. In (Ref. 20), the authors extend their model to include the energy equation and therefore, can predict the temperature field in the gas film. While the model includes calculation of the temperature field, it does not include the thermal deformations of the foil structure, which is believed to detract significantly from the load capacity of gas foil bearings. The results indicate an increase in load capacity as temperature increases, which is in direct opposition to experimental data obtained at GRC (DellaCorte (Ref. 21)). Foil thermal deformations are thought to be the leading cause of decreased load capacity at high temperature, offering a plausible cause for the discrepancy between the analysis and experiments.

Kim and San Andres (Ref. 22) use analytic expressions for foil structural stiffness linked to a Reynolds' equation hydrodynamic gas film solution. Using an axially averaged pressure, they report good agreement with experimental data for journal attitude angle and eccentricity at high static load conditions. At low load conditions the agreement is poor, due, they claim, to manufacturing inaccuracy of the tested bearings. Kim and San Andres (Ref. 23) develop a concept to determine a theoretical minimum film thickness for implementation in more complex analyses. They use this model in the previous analysis (Ref. 22) and in a more advanced analysis (Ref. 24), wherein they model the top foil with 1-D and 2-D finite elements. They report that both advancements greatly increase computational efficiency, yet the 2-D model does not reap great benefits over the 1-D model. Forced axial flow has been identified as an effective mechanism for thermal management in foil journal bearings (Ref. 25). In Reference 26, San Andres and Kim identify an unintended beneficial byproduct of axial flow driven by end pressurization, enhanced rotordynamic stability. Their analytical results correlate well with experimentally observed delayed instability.

\section{Assessment of Analysis Capability}

The previous discussion is a review of the literature on foil bearing predictive techniques. While it is important to know the work that has been done to facilitate modeling of gas foil bearings, the desired end result is a comprehensive analysis tool designers can use to build foil bearing hardware. With that result in mind, the following discussion and assessment of one of the techniques listed above seeks to determine, by way of modeling an existing test rig, if hardware could reasonably be designed using current tools. 
The analysis tool being assessed is called XLGFBTH, and is based on the work of San Andres and Kim (Refs. 22 to 24). XLGFBTH uses a Microsoft Excel Graphical User Interface to make data entry and output easy and readily available for most users. The code gives the user control over all pertinent bearing parameters allowing analysis of most bump-type foil bearing designs. The sub-structure stiffness distribution is calculated separately, before the main analysis routine. Thus, with some programming skill, bearing designs other than bump-type designs may be possible. The program runs a number of operating conditions including multiple cases for journal speed and (a) applied load or (b) journal eccentricity, with selections of force coefficients evaluation for varying whirl frequency or fixed whirl frequency, usually synchronous with journal speed.

The program graphical output includes plots for the pressure, film thickness and top foil deflection fields; and graphical and tabular output for the bearing journal eccentricity and attitude angle, minimum film thickness, torque and power loss, bearing structural stiffness, and stiffness and damping force coefficients versus the specified load and journal speed. Similar output parameters are found when the journal eccentricity is specified; however in this case, the program solves for the bearing reaction force.

The output is easy to visualize using the spreadsheet interface. Some example output is shown in Figures 2 to 5 . The major potential drawback to this code is its use of empirically derived characteristics used in the modeling of the structural stiffness and damping. There are two parameters, namely the sub-structure loss factor and the top foil stiffening factor, that must be input to the analysis. There are suggested values for these parameters, based upon empirical correlations. However, if one were to analyze bearings significantly different from those used in the correlations, these parameters would be relative unknowns, thus requiring experimental efforts to determine them.

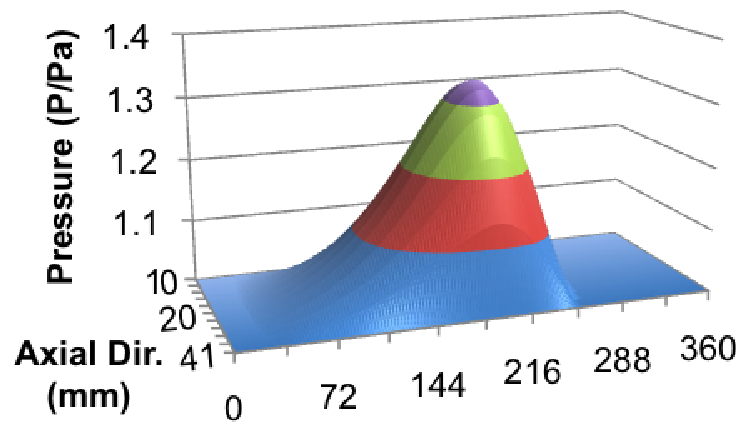

Angular Coordinate (deg)

Figure 2.-Predicted pressure field in a $50.8 \mathrm{~mm}$ generation I gas foil bearing operating at $60,000 \mathrm{rpm}, 20 \mathrm{n}$ static load.

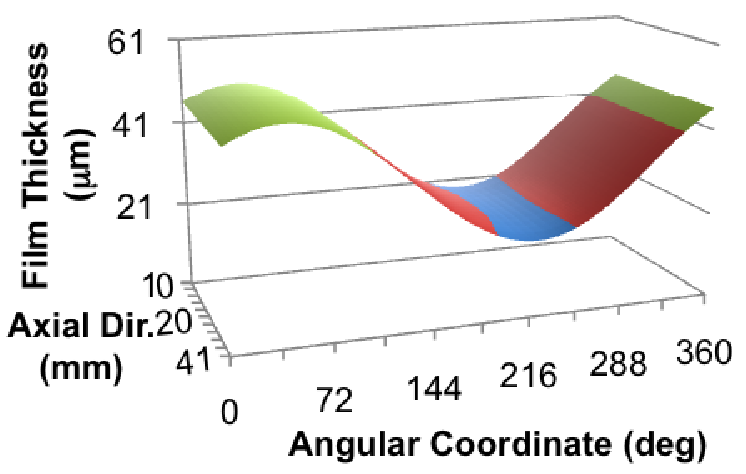

Figure 3.-Predicted film thickness field in a $50.8 \mathrm{~mm}$ generation I gas foil bearing operating at $60,000 \mathrm{rpm}, 20 \mathrm{n}$ static load.

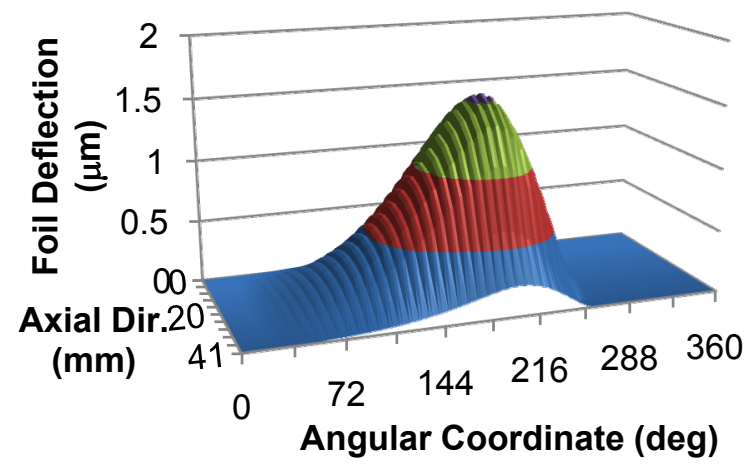

Figure 4.-Predicted top foil deflection field in a $50.8 \mathrm{~mm}$ generation I gas foil bearing operating at 60,000 rpm, $20 \mathrm{n}$ static load.

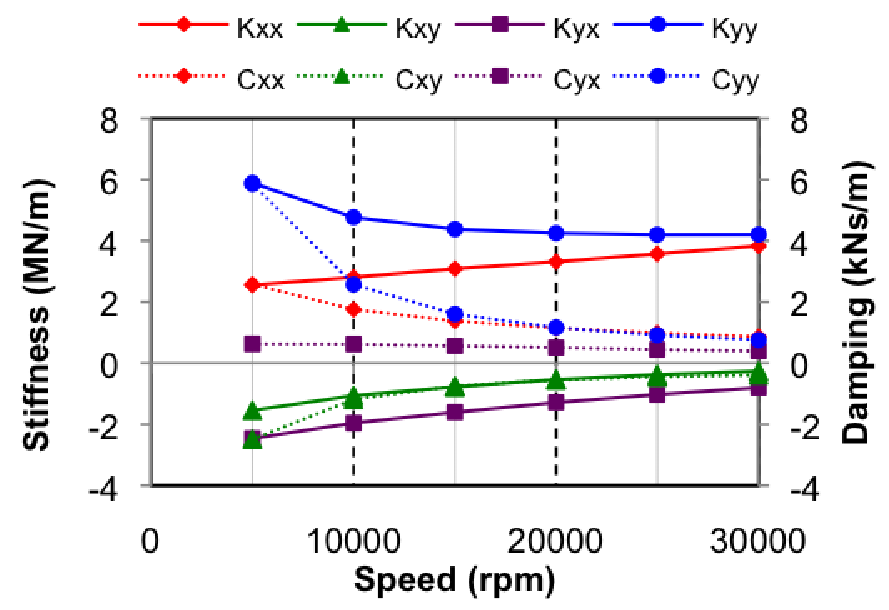

Figure 5.-Predicted (synchronous speed) stiffness and damping coefficients versus journal speed for a generation I gas foil bearing with $20 \mathrm{n}$ static load (y-direction). 
Note that the structural loss factor is a measure of the mechanical energy dissipation characteristics of the bumps sliding against the bearing inner diameter. The loss factor is a function of the material characteristics and surface conditions, load amplitude and frequency, as well as the environmental conditions; including atmospheric pressure, gaseous content, and humidity.

The top foil stiffening factor is a measure of the anisotropic elastic properties which depend on the forming process of the top foil. For example, annealed flat and conformed shells offer significantly different material properties along their principal axes.

For generality, the selection of the top foil stiffening factor and bearing structural loss factor are left to the user. This enables flexibility in the code to analyze bearing designs different from those discussed here and benchmarked with the analysis tool. Experimental work may be required to arrive at appropriate values for these two parameters, however, for typical bump-type bearings resembling those in this paper, suggested values are given based on a significant volume of empirical work (Refs. 4, 27 to 29).

The average user of this code will not have a bearing or rotor system in hand when using the code to design a turbomachine, and therefore will have no way to compare the results to measured response. Thus, the purpose of this paper is to determine if the analysis code adequately represents the physics of the particular problem class assessed herein while using recommended procedures and parameters where available, and reasonable assumptions elsewhere. For that reason, the recommended value for foil stiffening factor (4), and a reasonable guess at the loss coefficient (the code recommends using the friction coefficient, 0.2 is assumed) are used, and no attempt is made to evaluate the prediction sensitivity through parametric perturbation.

\section{Methodology for Assessment of Rotordynamic Predictive Capability}

The procedure used to evaluate the capability of XLGFBTH to predict the rotordynamic behavior of machinery is to first predict the rotordynamic response of a foil bearing test rig (Ref. 30) at GRC. The test rig, Figure 6, consists of a gas foil bearing supported rotor system capable of speeds ranging up to $60,000 \mathrm{rpm}$ in any number of configurations with instrumentation and data acquisition to observe and record the rotor response. In this case, the rotor configuration is simple, as shown in detail below, for easy modeling in a rotordynamics analysis package. Two foil bearings manufactured at GRC are used in the rotor simulator for the evaluation of the bearing predictive tool. No specific break-in procedure was performed on these bearings because typical break-in procedures require many high-temperature start/stop cycles (Ref. 31), of which this test rig is incapable. It is worth noting, however, that the rotor was chrome plated resulting in a very smooth and consistent surface much like one would

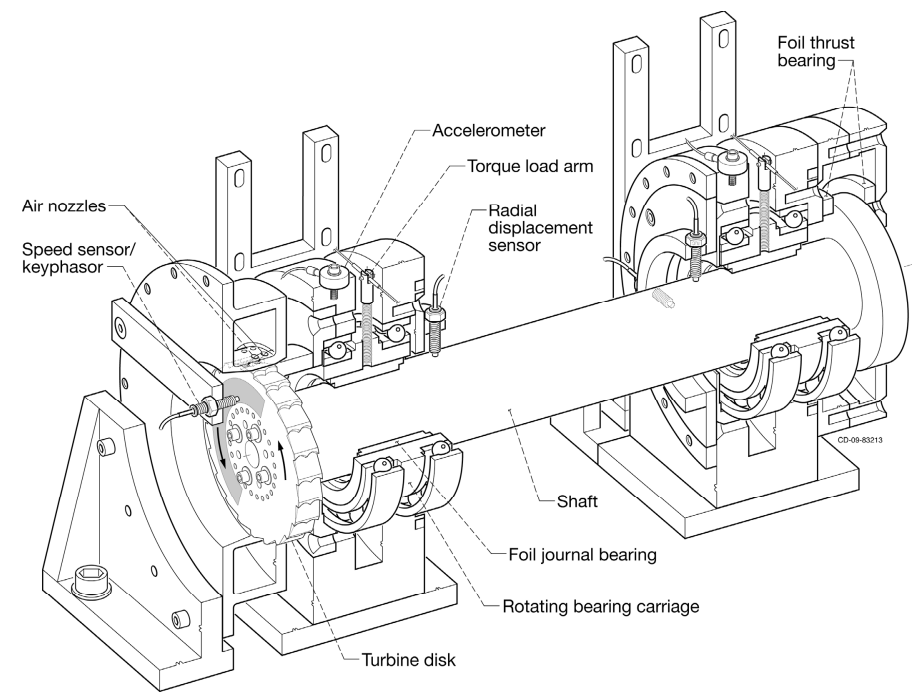

Figure 6.-Schematic of GRC foil bearing rotordynamic test rig.

expect of the typical foil bearing shaft coatings after a break-in procedure.

The first step, is to make the two foil journal bearings, and predict their rotordynamic coefficients using XLGFBTH. In order to predict their performance, the nominal bearing clearance must be known. One could ascertain the clearance by calculating the stack-up height of the bump and top foils, and subtracting that from the difference between the inner diameter of the bearing shell and the outer diameter of the shaft. There can be uncertainty in this method due to manufacturing variations, particularly in the bump foils. Therefore, in this case, a relatively new test rig at GRC, called the load deflection test rig and shown in Figure 7, is used to determine the nominal clearance.

A foil bearing is mounted in the load deflection test rig and subjected to static loads in opposing directions. A cable pulls upward on the bearing using dead weights, while a cable connected through a load cell to a pneumatic cylinder pulls downward. By varying the pressure to the pneumatic loader, one can apply loads ranging from positive $178 \mathrm{~N}$ (upward) to negative $178 \mathrm{~N}$ (downward). This is done in a stepwise fashion while monitoring and recording the displacement of the bearing relative to the stationary (nearly rigid) solid shaft running through it. The result of this test is a curve of deflection versus load for a range of loads on both sides of zero, as shown in Figure 8 for a typical bearing. As the figure shows, the shape of the load deflection curve is typically somewhat like an "S" with a region near zero load where the slope is very steep denoting a large flexibility. This steep part of the curve is due to the fact that near zero load, the bearing is nearly centered on the shaft and it has very low stiffness in the radial direction. As the load increases, and the bearing moves further away from center, the bumps on the side opposite the load become active, deforming as the load increases. At that point, the stiffness of the bearing increases and the slope of the 


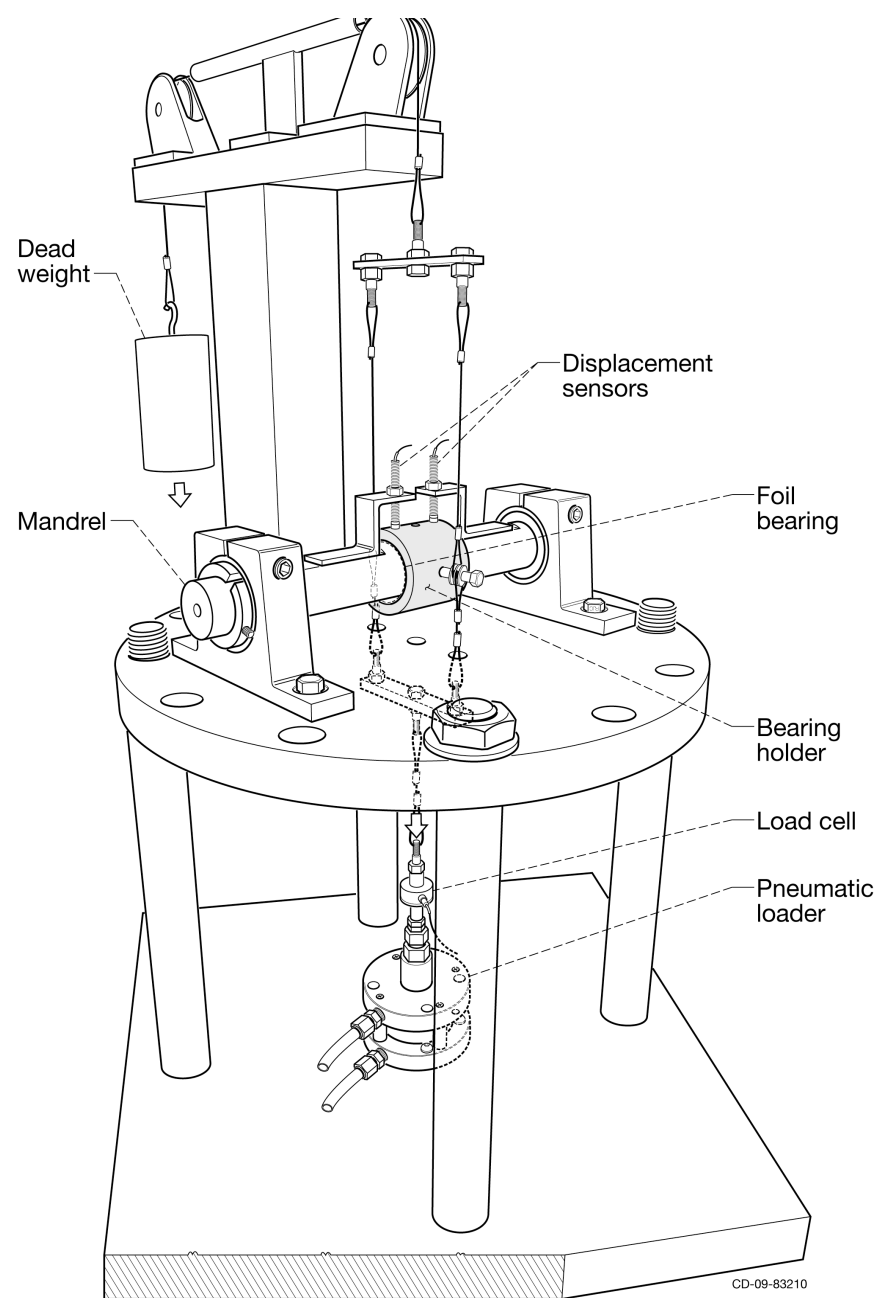

Figure 7.-Schematic of the GRC load deflection test rig.

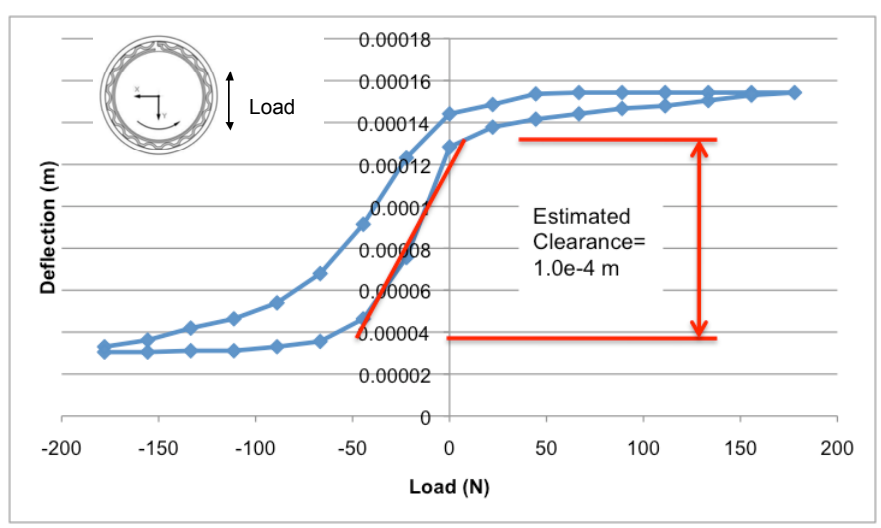

Figure 8.-A sample deflection versus static load test results for the right bearing.

load deflection curve decreases. The region of the curve where the slope is steep is defined as the nominal bearing clearance, and the region where the slope is low is taken as the structural flexibility ( $1 /$ stiffness) of the foil bearing. The load deflection curve also has some hysteresis, meaning that the bearing does not follow the same path during the unloading cycle as it does during the loading cycle. This well known behavior is indicative of material damping, and the size of the loop evidences the magnitude of the energy dissipation. It is important to note that a given foil bearing's load versus deflection curve (and hysteresis loop) depends on the orientation of the load relative to the weld connection line for the top foil and bump foil strips. Hence, differing load orientations will lead to different ad-hoc clearances and substantially different loss factors. Thus, it is important to conduct the measurements with the bearing positioned in the same direction as the static load will act on the test rig.

The clearance estimate is important because most foil bearing design tools typically assume there is some clearance between the rotor and the foil to define (initially) the air gap. Therefore, the clearance is an input needed to run an analysis. Using the results from the load deflection tests, the left bearing diametral clearance is estimated as $68 \mu \mathrm{m}$, and the right bearing diametral clearance is estimated as $100 \mu \mathrm{m}$, for the analysis.

The most important realization from the load versus deflection data is that the structure of a foil bearing is highly nonlinear, with distinctive soft and hardening regions. In nonlinear dynamics, this structural behavior will give rise to forced sub- harmonic motions, not to be confused with instability associated to loss of damping (Ref. 32).

In the interest of making the data useful to other researchers, the geometry of the test set-up must be presented. The general description of the test rig can be found in Howard (Ref. 30), and the specific geometry of the rotor is included in Figure 9 to enable others to model the rotor bearing system for assessment of future analysis tools. To make the data useful to a broad audience, the foil bearings used were of an opensource design, enabling the full details of the geometry to be reported. Dellacorte, et al. (Ref. 21) describe the manufacturing technique and basic geometry used for the journal bearings. Table 1 lists the specific geometry of the test foil bearings, whose bump geometry is identical to that in Reference 21.

Using the bearing geometry from Table 1 , the estimates for clearances, and the weight of the rotor $(67.2 \mathrm{~N})$, XLGFBTH was used to calculate the bearing synchronous rotordynamic force coefficients for use in the rotordynamic model predictions. Tables 2 and 3 give the calculated stiffness and damping coefficients for each bearing, and Figure 10 gives the resulting eccentricity and eccentricity angle.

The geometry and physical attributes of the rotor must also be known to appropriately model the system rotordynamics. Figure 9 shows the geometry of the rotor, the solid middle section of which is 4140 steel, and the two disks attached to the ends are 17-4 stainless steel. The rotor assembly weighs $67.2 \mathrm{~N}$, and is symmetric about the center of mass except for small cutouts on the outside diameter of one disk for turbine buckets (the small effect of the buckets and the added mass of the bolts attaching the disks was neglected in the model). 
TABLE 1.-FOIL JOURNAL BEARING GEOMETRY

\begin{tabular}{|l|c|}
\hline Diameter & $50.8 \mathrm{~mm}$ \\
\hline Length & $40.6 \mathrm{~mm}$ \\
\hline Foil thickness (bump and top) & $0.102 \mathrm{~mm}$ \\
\hline Bump height & $0.51 \mathrm{~mm}$ \\
\hline Bump pitch & $3.17 \mathrm{~mm}$ \\
\hline Bump length & $2.54 \mathrm{~mm}$ \\
\hline Bump foil angular extent & $360^{\circ}$ \\
\hline Foil material & Inconel 718 \\
\hline Structural loss coefficient & 0.2 \\
\hline Top foil stiffening factor & 4 \\
\hline Static load, each bearing & $33.6 \mathrm{~N}$ \\
\hline
\end{tabular}

TABLE 2.-STIFFNESS AND DAMPING COEFFICIENTS FOR LEFT BEARING. EVALUATED AT FREQUENCY $=$ SYNCHRONOUS SPEED, STATIC LOAD $=33.6 \mathrm{~N}($ IN Y DIRECTION)

\begin{tabular}{|c|c|c|c|c|c|c|c|c|}
\hline $\begin{array}{c}\text { Speed, } \\
\mathrm{rpm}\end{array}$ & $\begin{array}{c}\mathrm{Kxx}, \\
\mathrm{MN} / \mathrm{m}\end{array}$ & Kxy & Kyx & Kyy & \multicolumn{2}{c|}{$\begin{array}{c}\text { Cxx, } \\
\mathrm{kNs} / \mathrm{m}\end{array}$} & Cxy \\
\hline 5000 & 2.55 & -1.55 & -2.46 & 5.89 & 2.58 & -2.49 & 0.627 & 5.86 \\
\hline 10000 & 2.81 & -1.06 & -1.96 & 4.77 & 1.76 & -1.19 & 0.621 & 2.57 \\
\hline 15000 & 3.09 & -0.777 & -1.61 & 4.38 & 1.38 & -0.751 & 0.564 & 1.61 \\
\hline 20000 & 3.31 & -0.538 & -1.29 & 4.25 & 1.15 & -0.550 & 0.506 & 1.16 \\
\hline 25000 & 3.57 & -0.376 & -1.03 & 4.20 & 0.986 & -0.446 & 0.447 & 0.915 \\
\hline 30000 & 3.83 & -0.265 & -0.801 & 4.21 & 0.864 & -0.385 & 0.393 & 0.757 \\
\hline
\end{tabular}

TABLE 3.-STIFFNESS AND DAMPING COEFFICIENTS FOR THE RIGHT BEARING. EVALUATED AT FREQUENCY $=$ SYNCHRONOUS SPEED, STATIC LOAD $=33.6 \mathrm{~N}($ IN Y DIRECTION)

\begin{tabular}{|c|c|c|c|c|c|c|c|c|}
\hline $\begin{array}{c}\text { Speed, } \\
\mathrm{rpm}\end{array}$ & $\begin{array}{c}\text { Kxx, } \\
\mathrm{MN} / \mathrm{m}\end{array}$ & Kxy & Kyx & Kyy & \multicolumn{2}{c|}{$\begin{array}{c}\text { Cxx, } \\
\mathrm{kNs} / \mathrm{m}\end{array}$} & Cxy & Cyx \\
\hline 5000 & 1.53 & -1.37 & -2.11 & 5.79 & 1.16 & -1.80 & 0.106 & 5.10 \\
\hline 10000 & 1.64 & -1.08 & -1.84 & 4.39 & 0.818 & -0.962 & 0.157 & 2.23 \\
\hline 15000 & 1.76 & -0.940 & -1.68 & 3.78 & 0.661 & -0.642 & 0.162 & 1.36 \\
\hline 20000 & 1.82 & -0.803 & -1.51 & 3.44 & 0.559 & -0.465 & 0.168 & 0.953 \\
\hline 25000 & 1.91 & -0.711 & -1.39 & 3.22 & 0.489 & -0.360 & 0.165 & 0.726 \\
\hline 30000 & 1.98 & -0.629 & -1.28 & 3.08 & 0.437 & -0.291 & 0.161 & 0.583 \\
\hline
\end{tabular}

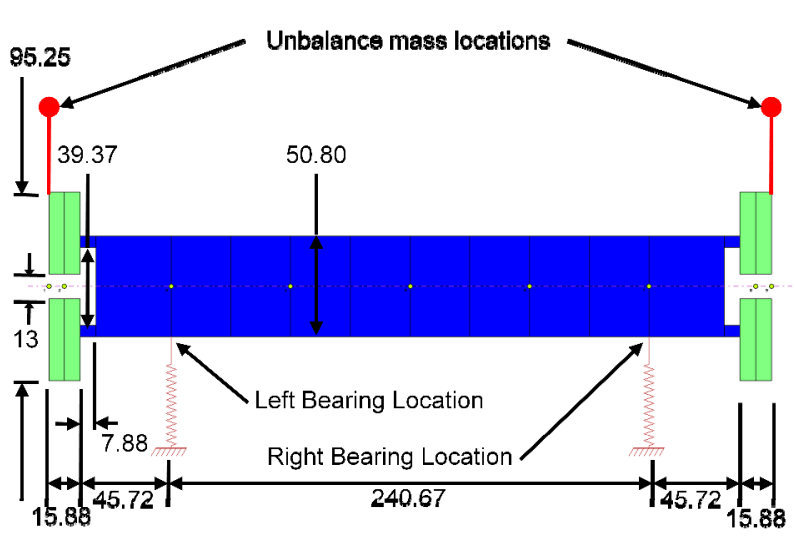

Figure 9.- Schematic of the rotor layout used in the rotordynamic model with dimensions in $\mathrm{mm}$.
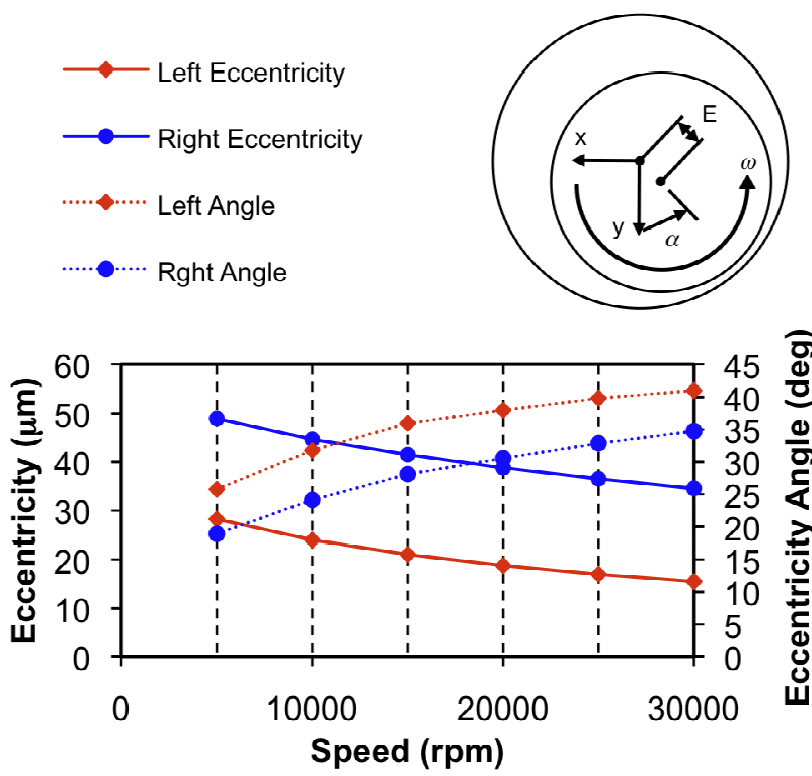

Figure 10.-Plot of predicted eccentricity and eccentricity angle for the left and right foil journal bearings. 
Prior to running on the foil bearings, the rotor assembly was balanced with a residual imbalance of $4.2 \mathrm{~g}-\mathrm{mm}$ at $46^{\circ}$ on the left end and $7.5 \mathrm{~g}-\mathrm{mm}$ at $87^{\circ}$ on the right end, as determined by a balance machine at GRC. These two magnitudes were used as the unbalance distribution in the model.

The rotordynamic model was used to calculate the synchronous response at each of the locations measured in the test rig to assess the capability of the predictive tool. A Bode

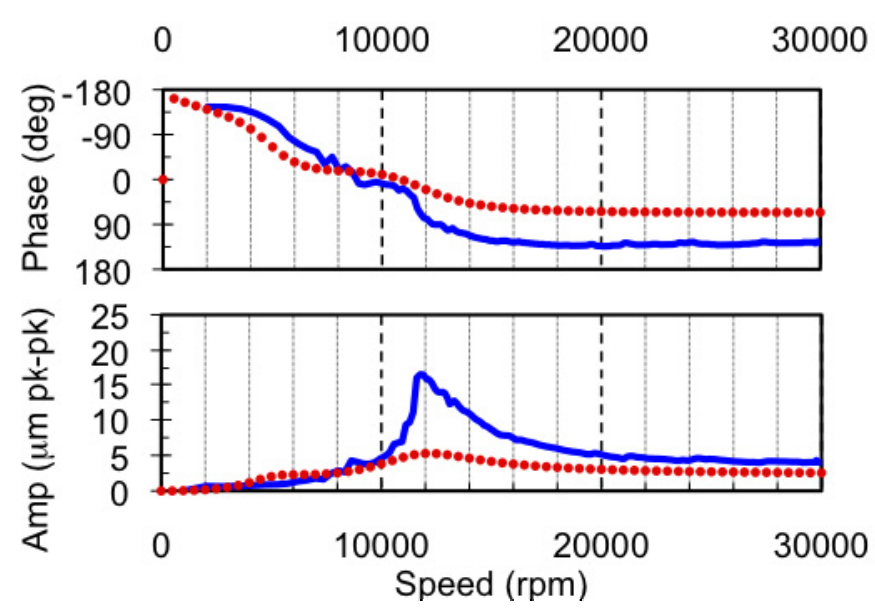

Figure 11.-Bode plots: measured (solid) and predicted (dotted) amplitude and phase of rotor unbalance response at left bearing, vertical direction.

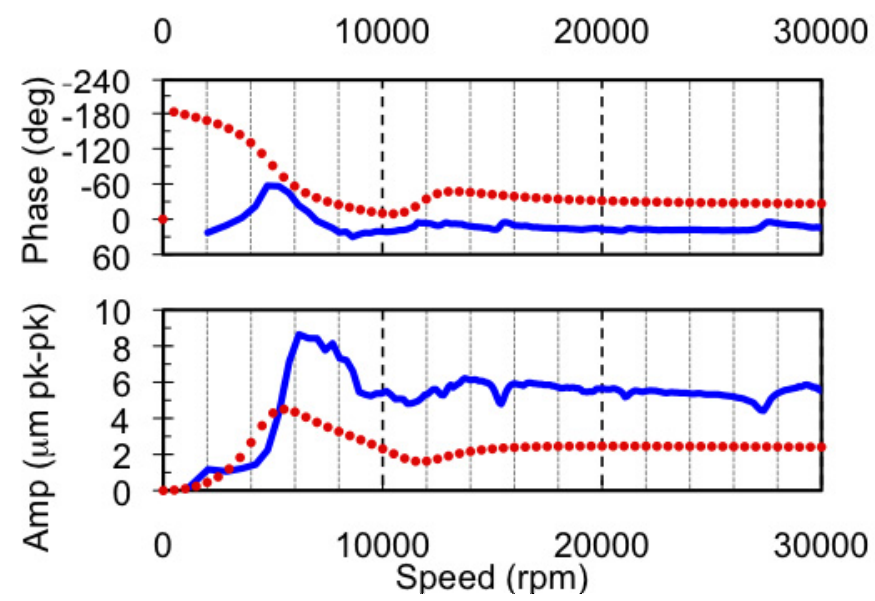

Figure 12.-Bode plots: measured (solid) and predicted (dotted) amplitude and phase of rotor unbalance response at left bearing, horizontal direction. plot presents the amplitude and phase of synchronous response. This is a convenient plot on which to focus attention because it relays information about the rotor response to unbalance as well as critical speeds of the system, both useful measures of a model's capability to capture the physics of the system. The predicted Bode plots are shown in the following section in Figures 11 to 14 where they are compared to the experimentally observed response.

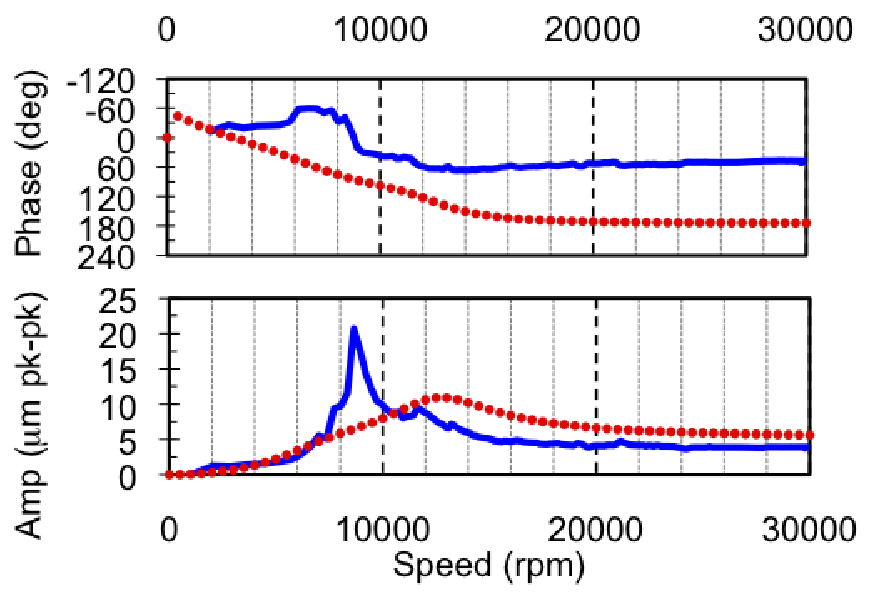

Figure 13.-Bode plots: measured (solid) and predicted (dotted) amplitude and phase of rotor unbalance response at right bearing, vertical direction.

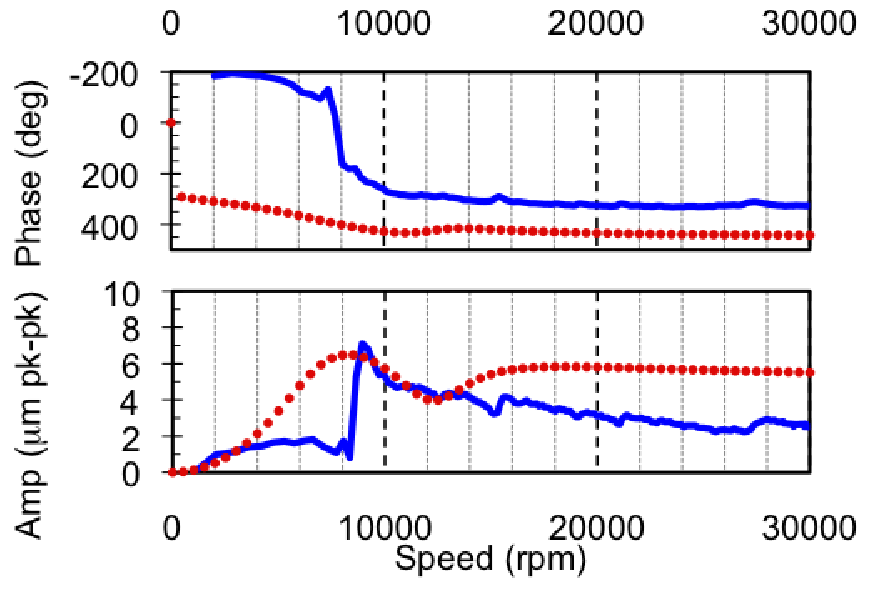

Figure 14.-Bode plots: measured (solid) and predicted (dotted) amplitude and phase of rotor unbalance response at right bearing, horizontal direction. 


\section{Comparison of Predicted and Experimental Rotor Response}

After the load deflection tests were completed, the bearings and rotor were assembled in the rotor simulator test rig. Initially, the rotor was spun to a low speed (approx. $10,000 \mathrm{rpm}$ ) slightly above its lift-off speed and checked out for smooth operation. This test was conducted to determine if the bearings were capable of supporting the weight of the rotor, and that nothing unusual, like thermal run-away, would prevent the test from reaching completion. Since bearing load capacity increases with speed, low speed conditions such as this are more likely to result in overload conditions and thermally unstable operation. So, while being rotordynamically less challenging, low speed operation is typically more stressful on the foil bearings in terms of load than moderate speed operation. The initial behavior of the bearings was acceptable, and the rotor was spun slowly up to $30,000 \mathrm{rpm}$. After a short time, the air supply to the turbine was shut off and the rotor coasted to a stop. The speedup/coast-down cycle was repeated another time to observe the repeatability of the data. The maximum speed of $30,000 \mathrm{rpm}$ was chosen as a result of data acquisition and dynamics of the system. Speeds higher than $30,000 \mathrm{rpm}$ result in a twofold decrease in data resolution (32 samples per revolution compared to 64) and nothing of interest happens between $30,000 \mathrm{rpm}$ and the maximum speed of $60,000 \mathrm{rpm}$ due to the bending critical speed occurring above that threshold.

There are four displacement sensors on the test rig, two near each bearing with one at $0^{\circ}$ (horizontal) and one at $90^{\circ}$ (vertical), resulting in four measured response plots. Figures 11 to 14 show four sets of two Bode plots (amplitude and phase) for the rotor supported on the two GRC made foil bearings. Each set of two plots contains first the predicted unbalance response (amplitude and phase) from above in dotted lines, and the measured unbalance response in solid lines (slow-roll compensated for mechanical and electrical run-out) for a given displacement sensor location. The experimental data does not extend below about $1000 \mathrm{rpm}$ due to very rapid deceleration of the test rotor leading to unreliable keyphasor data.

\section{Discussion}

The first thing one might notice from comparison of the predicted response curves to the measured response curves is that both contain localized peak responses for the various directions at speeds between about 5,000 and 12,000 rpm. A closer look reveals that at the left end of the rotor, Figures 11 and 12, there is a mostly vertical resonance at around $12,000 \mathrm{rpm}$, and a mostly horizontal resonance with wider frequency content centered around 7,000 rpm. An immediate observation is that the predicted response captures the frequency content in both directions very well. However, the amplitude is off by a factor of as much as 3 . The predicted phase lag agrees well in trend, but is shifted in both plots by a fairly constant amount. The amplitude and phase differences are consistent with incorrect unbalance magnitude and phase in the model. This is discussed in more detail later.

The comparison between prediction and experiment at the right end is less favorable, yet when assessing the prediction as a design tool, not altogether terrible. Looking at the horizontal plot first, Figure 14, there is a predicted peak response around 8,000 rpm. Experimentally, the resonance occurs at around 9,000 rpm, with a much narrower peak. In the vertical direction, Figure 13, there is a predicted resonance at around $12,000 \mathrm{rpm}$. Experimentally, there is a corresponding peak to the horizontal resonance at 9,000 rpm, and interestingly, another small peak at 12,000 with similar amplitude to the prediction. As with the left rotor end, the predicted amplitudes are lower than those experimentally observed, with the exception of the right end horizontal direction, see Figure 14. The phase predictions still generally have similar shapes, but are less consistent in the shift amount than the predictions for the right end response. The most glaring difference between predicted and observed response for this rotor system is the horizontal peak observed at the right end at around 9,000 rpm. This frequency corresponds to the large vertical response at the right end, which was captured in the prediction, but the horizontal component was not.

In summary of the predicted versus experimental unbalance response, there is general agreement between the two that two critical speeds exist in the speed range of 5,000 to $12,000 \mathrm{rpm}$. Experimentally, the first one occurs at around 9,000 rpm, and is elliptical in shape with larger horizontal amplitude on the left end, and larger vertical amplitude on the right. The second critical speed occurs at $12,000 \mathrm{rpm}$, and has a mostly vertical mode shape. In the predicted response, the first critical speed occurs around 7,000 rpm with large horizontal amplitude. The second critical speed agrees well with the experimental results, occurring at 12,000 rpm, with a mostly vertical mode shape.

While the predictions are not an exact representation of the observed unbalance response, they are quite close, and importantly show the correct trends. The model correctly predicts the existence of two critical speeds, and that the horizontally oriented mode occurs at a lower speed than the vertically oriented mode. The predicted frequency of the higher critical speed is quite good, and the lower one, while not as accurate, is still reasonably close, considering the large speed range of the machine (0 to 60,000 rpm).

As mentioned above, the model mostly under-predicts the amplitudes of the critical speeds by as much as a factor of 3 . The amplitude error is likely due to a lack of certainty in the residual unbalance (amplitude and phase angle) from the balance procedure.

Errors in the magnitude and/or phase of the unbalance vectors could come from several possible sources. Measurement uncertainty due to balance machine resolution accuracy and repeatability is one potential source. Another disassembly and re-assembly of the rotor required to mount it in the test rig. Small changes in angular position of the disks 


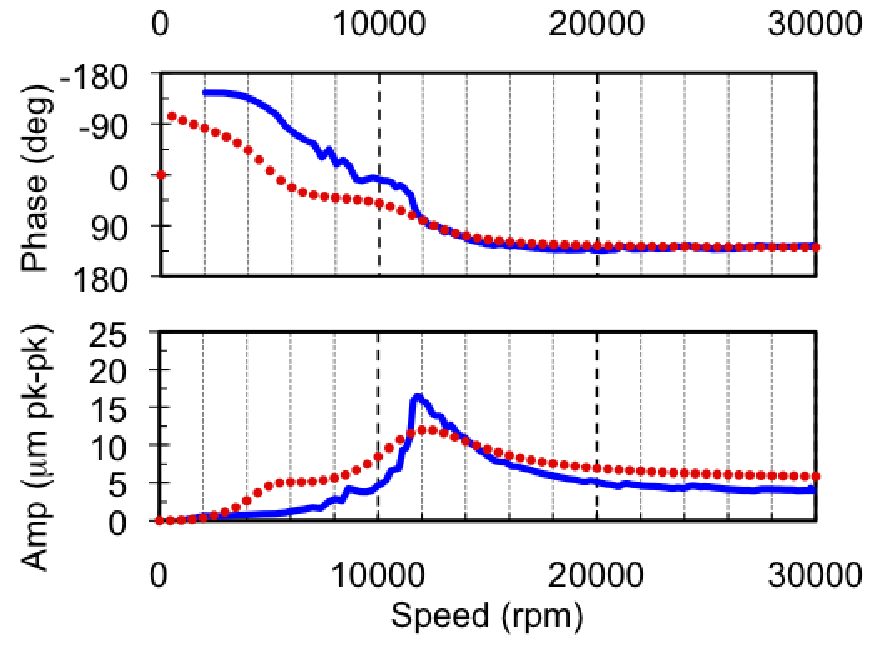

Figure 15.-Bode plots: measured (solid) and predicted (dotted) amplitude and phase of rotor unbalance response at left bearing, vertical direction using revised unbalance vectors in the rotordynamic model.

relative to the shaft will result in changes to the unbalance condition. While these changes are small, the magnitude of the unbalance is small as well. Thus, it is conceivable that this could contribute to the discrepancies in response amplitude seen in the comparisons above. Whatever the source, it cannot be ruled-out that the unbalance vectors used in the model contain some level of uncertainty.

The fact that the unbalance vectors used in the model are likely in error does not detract from the usefulness of the foil bearing predictive code as a design tool. To illustrate that a better match between predicted and observed unbalance response is possible, different unbalance vectors were used in the rotordynamic model to verify that good agreement is possible simply by using different unbalance inputs to the model. Figure 15 shows the same response data from Figure 11, but with a set of revised unbalance vectors to improve the agreement between predicted and observed unbalance response. The revised unbalance vectors are: $8.5 \mathrm{~g}-\mathrm{mm}$ at $150^{\circ}$ on the left end, and $7.56 \mathrm{~g}-\mathrm{mm}$ at $190^{\circ}$ on the right end. Similar improvements were obtained for the other three probe locations shown in Figures 11 to 14, but are not shown here for brevity. It should be noted that the revised unbalance vectors are not presumed to be correct, they were simply intended to illustrate that the bearing rotordynamic coefficients calculated using XLGFBTH can result in quite good agreement to experimental data.

Another contributing factor to the differences in the prediction to the experiment are the estimates used for bearing clearance. The load deflection tests described above were done with the bearings in two angular orientations, with the load direction in line with the bearing vertical direction and with the load direction oriented in the bearing horizontal direction resulting in slightly different clearance values. Also, as shown in Figure 8, due to the hysteresis effect, there is an upper load deflection curve and a lower curve. One could chose to use the upper, the lower, an average, or some other means to determine the clearance. Clearly, there is some subjectivity in modeling the clearance of a foil bearing, and the variations involved with which method chosen could lead to some variation in predicted bearing properties.

In addition, the foil stiffening factor and the bearing structural loss factor are parameters that the user can change to fine-tune the results of the analysis. For example, the predicted bearing damping is overestimated as evidenced by the width of the peaks in the Bode plots. This is likely a result of the structural loss coefficient chosen. If this were an academic exercise to try to get the best agreement, the analysis could be iterated to find an optimum solution. Because of the nature of this paper, to assess the code as a typical user might exercise it, the sensitivity of the results to these parameters was not assessed.

\section{Summary}

A new analysis tool for gas foil bearings is assessed for its ability to predict dynamic response of a foil bearing supported test rig. Rotordynamic force coefficients are calculated for bearings made in-house and installed in the test rig, and a rotordynamic model predicts the unbalance response. The unbalance response is then measured experimentally, and compared to the prediction.

Overall, the degree to which the predictive tool captures the critical speeds is impressive considering that there is some uncertainty in the way the clearance was determined for input into the analysis tool. The discrepancy between the observed and predicted amplitudes of motion are of concern, but are more likely related to modeling characteristics other than those predicted by the foil bearing analysis tool, such as residual unbalance and clearance. The usefulness of the predictive tool will be in its ability to help engineers design around critical speeds, which it appears to be reasonably capable of doing at the present.

Of primary interest in this paper is the predictive capability of the code in regard to bearing rotordynamic coefficients. For discussion of other capabilities of the code with experimental validation see References $24,26,33$ to 34 . Reference 33 extends the predictive gas foil bearing analysis to high temperature operation with thermal energy transport and management, as well as accounting for elastic and thermally induced changes in materials and operating clearance. Reference 34 provides temperature and rotordynamic measurements in a hot rotor-foil bearing system and comparisons to predictions from the extended elastothermohydrodynamic model. 


\section{References}

1. Ku, C.P.R., and Heshmat, H., 1992, "Compliant Foil Bearing Structural Stiffness Analysis: Part I - Theoretical Model Including Strip and Variable Bump Foil Geometry," ASME J. of Tribology, 114(2), pp. 394-400.

2. Ku, C.P.R., and Heshmat, H., 1993, "Compliant Foil Bearing Structural Stiffness Analysis: Part II Experimental Investigation," ASME J. of Tribology, 115(3), pp. 364-369.

3. Ku, C.P.R., and Heshmat, H., 1994, "Effects of Static Load on Dynamic Structural Properties in a Flexible Supported Foil Journal Bearing," ASME J. of Vibration and Acoustics, 116(3), pp. 257-262.

4. Rubio, D., and San Andres, L., 2006, "Bump-Type Foil Bearing Structural Stiffness: Experiments and Predictions," ASME J. of Eng. For Gas Turbines and Power, 128(3), pp. 653-660.

5. Le Lez, S., Arghir, M., and Frene, J., 2007, "Static and Dynamic Characterisation of a Bump-Type Foil Bearing Structure," ASME J. of Tribology, 129(1), pp. 75-83.

6. Lee, Y-B., Jo, J-H., Park, D-J., Kim, C-H., and Rhim, YC., 2006, "Dynamic Characteristics of Bump Foils Considering with Thermal Effect in Air Foil Bearings," STLE/ASME Paper No. IJTC2006-12189.

7. Heshmat, H, Walowit, J.A., and Pinkus, O., 1983, "Analysis of Gas-Lubricated Foil Journal Bearings," ASME J. of Lubrication Technology, 105(3), pp. 647655.

8. Heshmat, H, Walowit, J.A., and Pinkus, O., 1983, "Analysis of Gas-Lubricated Compliant Thrust Bearings," ASME J. of Lubrication Technology, 105(4), pp. 638646.

9. Iordanoff, I., 1999, "Analysis of an Aerodynamic Compliant Foil Thrust Bearing: Method for a Rapid Design," ASME J. of Tribology, 121(4), pp. 816-822.

10. Heshmat, C.A., Xu, D.S., and Heshmat, H., 2000, "Analysis of Gas Lubricated Foil Thrust Bearings Using Coupled Finite Element and Finite Difference Methods," ASME J. of Tribology, 122(1), pp. 199-204.

11. Bruckner, R.J., 2004, "Simulation and Modeling of the Hydrodynamic, Thermal, and Structural Behavior of Foil Thrust Bearings," Doctoral Dissertation, Case Western Reserve University, Cleveland.

12. Peng, J-P., and Carpino, M., 1993, "Calculation of Stiffness and Damping Coefficients for Elastically Supported Gas Foil Bearings," ASME J. of Tribology, 115(1), pp. 20-27.

13. Peng, J-P., and Carpino, M., 1994, "Coulomb Friction Damping Effects in Elastically Supported Gas Foil Bearings," STLE Tribology Tansactions, 37(1), pp. 9198.

14. Carpino, M., Medvetz, L.A., and Peng, J-P., 1994, "Effects of Membrane Stresses in the Prediction of Foil Bearing Performance," STLE Tribology Transactions, 37(1), pp. 43-50.
15. Carpino, M., Peng, J-P., and Medvetz, L.A., 1994, "Misalignment in a Complete Shell Gas Foil Journal Bearing," STLE Tribology Transactions, 37(4), pp. 829 835.

16. Carpino, M., and Talmadge, G., 2003, "A Fully Coupled Finite Element Formulation for Elastically Supported Foil Journal Bearings," STLE Tribology Transactions, 46(4), pp. 560-565.

17. Carpino, M., and Talmadge, G., 2006, "Prediction of Rotor Dynamic Coefficients in Gas Lubricated Foil Journal Bearings with Corrugated Sub-Foils," STLE Tribology Transactions, 49(3), pp. 400-409.

18. Lee, N.S., Choi, D.H., Lee, Y.B., Kim, T.H., and Kim, C.H., 2002, "The Influence of the Slip Flow on SteadyState Load Capacity, Stiffness and Damping Coefficients of Elastically Supported Gas Foil Bearings," STLE Tribology Transactions, 45(4), pp. 478-484.

19. Peng, Z.-C., and Khonsari, M.M., 2004, "Hydrodynamic Analysis of Compliant Foil Bearings with Compressible Air Flow," ASME J. of Tribology, 126(3), pp. 542-546.

20. Peng, Z.-C., and Khonsari, M.M., 2006, "A Thermohydrodynamic Analysis of Foil Journal Bearings" ASME J. of Tribology, 128(3), pp. 534-541.

21. DellaCorte, C, Radil, K.C., Bruckner, R.J., and Howard, S.A., 2007, "Design, Fabrication and Performance of Open Source Generation I and II Compliant Hydrodynamic Gas Foil Bearings," NASA/TM-2007214691/ARL-TR-4102.

22. Kim, T.H., and San Andrés, L., 2005, "Heavily Loaded Gas Foil Bearings: A Model Anchored to Test Data," ASME Paper No. GT2005-68486.

23. Kim, T.H., and San Andrés, L., 2006, "Limits for High Speed Operation of Gas Foil Bearings," ASME J. of Tribology, 128(3), pp. 670-673.

24. San Andrés, L., and Kim, T.H., 2007, "Improvements to the Analysis of Gas Foil Bearings: Integration of Top Foil 1D and 2D Structural Models," ASME Paper No. GT2007-27249.

25. Radil, K., DellaCorte, C., Bruckner, R., and Zesotek, M., 2007, "Thermal Management Techniques for Oil-Free Turbomachinery Systems," STLE Tribology Transactions, 50, pp. 319-327.

26. Kim, T.H., and San Andrés, L., 2009, "Effect of Side Feed Pressurization on the Dynamic Performance of Gas Foil Bearings: A Model Anchored to Test Data," ASME J. of Eng. Gas Turbines Power, 131(1), pp. 012501.

27. Rubio, D., and San Andrés, L., 2007, "Structural Stiffness, Dry Friction Coefficient, and Equivalent Viscous Damping in a Bump-Type Foil Gas Bearing," ASME J. of Eng. Gas Turbines Power, 129(2), pp. 494 502.

28. Kim, T.H., Breedlove, A.W., and San Andres, L., 2008, "Characterization of Foil Bearing Structure for Increasing Shaft Temperature: Part I-Static Load Performance," ASME Paper No. GT2008-50567. 
29. Kim, T.H., Breedlove, A.W., and San Andres, L., 2008, "Characterization of Foil Bearing Structure for Increasing Shaft Temperature: Part II-Dynamic Force Performance," ASME Paper No. GT2008-50570.

30. Howard, S.A., 2007, "A New High-Speed Oil-Free Turbine Engine Rotordynamic Simulator Test Rig," NASA/TM-2007-214489.

31. Radil, K.C., and DellaCorte, C., 2002, "The Effect of Journal Roughness and Foil Coatings on the Performance of Heavily Loaded Foil Bearings," Triboloy Transactions, 45(2), pp. 199-204.

32. San Andrés, L., and Kim, T. H., 2008, "Forced Nonlinear Response of Gas Foil Bearing Supported Rotors," Tribology International, 41(8), pp. 704-715.
33. San Andrés, L., and Kim, T. H., 2010, "Thermohydrodynamic Analysis of Bump Type Gas Foil Bearings: A Model Anchored to Test Data," ASME J. Eng. Gas Turbines Power, 132(4), pp. 10.

34. Kim, T.H., and San Andrés, L., 2010, "Thermohydrodynamic Model Predictions and Performance Measurements of Bump-Type Foil Bearing for Oil-Free Turboshaft Engines in Rotorcraft Propulsion Systems," ASME J. Tribol. 132(1), pp. 11. 


\begin{tabular}{|c|c|c|}
\hline \multicolumn{2}{|c|}{ REPORT DOCUMENTATION PAGE } & $\begin{array}{l}\text { Form Approved } \\
\text { OMB No. 0704-0188 }\end{array}$ \\
\hline \multicolumn{3}{|c|}{ 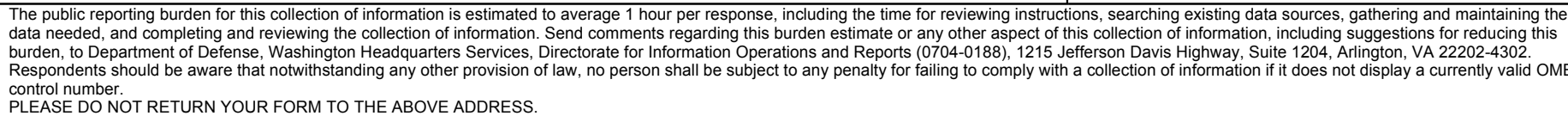 } \\
\hline $\begin{array}{l}\text { 1. REPORT DATE (DD-MM-YYYY) } \\
01-07-2010\end{array}$ & $\begin{array}{l}\text { 2. REPORT TYPE } \\
\text { Technical Memorandum }\end{array}$ & 3. DATES COVERED (From - To) \\
\hline \multirow{3}{*}{\multicolumn{2}{|c|}{$\begin{array}{l}\text { 4. TITLE AND SUBTITLE } \\
\text { A New Analysis Tool Assessment for Rotordynamic Modeling of Gas Foil Bearings }\end{array}$}} & 5a. CONTRACT NUMBER \\
\hline & & 5b. GRANT NUMBER \\
\hline & & 5c. PROGRAM ELEMENT NUMBER \\
\hline \multirow{3}{*}{\multicolumn{2}{|c|}{$\begin{array}{l}\text { 6. AUTHOR(S) } \\
\text { Howard, Samuel, A.; San Andres, Luis }\end{array}$}} & 5d. PROJECT NUMBER \\
\hline & & 5e. TASK NUMBER \\
\hline & & $\begin{array}{l}\text { 5f. WORK UNIT NUMBER } \\
\text { WBS 877868.02.07.03.01.01.04 }\end{array}$ \\
\hline \multicolumn{2}{|c|}{$\begin{array}{l}\text { 7. PERFORMING ORGANIZATION NAME(S) AND ADDRESS(ES) } \\
\text { National Aeronautics and Space Administration } \\
\text { John H. Glenn Research Center at Lewis Field } \\
\text { Cleveland, Ohio 44135-3191 }\end{array}$} & $\begin{array}{l}\text { 8. PERFORMING ORGANIZATION } \\
\text { REPORT NUMBER } \\
\text { E-17290-1 }\end{array}$ \\
\hline \multirow{2}{*}{\multicolumn{2}{|c|}{$\begin{array}{l}\text { 9. SPONSORING/MONITORING AGENCY NAME(S) AND ADDRESS(ES) } \\
\text { National Aeronautics and Space Administration } \\
\text { Washington, DC 20546-0001 }\end{array}$}} & $\begin{array}{l}\text { 10. SPONSORING/MONITOR'S } \\
\text { ACRONYM(S) } \\
\text { NASA }\end{array}$ \\
\hline & & $\begin{array}{l}\text { 11. SPONSORING/MONITORING } \\
\text { REPORT NUMBER } \\
\text { NASA/TM-2010-216354 }\end{array}$ \\
\hline \multicolumn{3}{|c|}{$\begin{array}{l}\text { 12. DISTRIBUTION/AVAILABILITY STATEMENT } \\
\text { Unclassified-Unlimited } \\
\text { Subject Categories: } 07 \text { and } 37 \\
\text { Available electronically at http://gltrs.grc.nasa.gov } \\
\text { This publication is available from the NASA Center for AeroSpace Information, 443-757-5802 }\end{array}$} \\
\hline
\end{tabular}

\section{SUPPLEMENTARY NOTES}

\section{ABSTRACT}

Gas foil bearings offer several advantages over traditional bearing types that make them attractive for use in high-speed turbomachinery. They can operate at very high temperatures, require no lubrication supply (oil pumps, seals, etc.), exhibit very long life with no maintenance, and once operating airborne, have very low power loss. The use of gas foil bearings in high-speed turbomachinery has been accelerating in recent years, although the pace has been slow. One of the contributing factors to the slow growth has been a lack of analysis tools, benchmarked to measurements, to predict gas foil bearing behavior in rotating machinery. To address this shortcoming, NASA Glenn Research Center (GRC) has supported the development of analytical tools to predict gas foil bearing performance. One of the codes has the capability to predict rotordynamic coefficients, power loss, film thickness, structural deformation, and more. The current paper presents an assessment of the predictive capability of the code, named XLGFBTH (Texas A\&M University). A test rig at GRC is used as a simulated case study to compare rotordynamic analysis using output from the code to actual rotor response as measured in the test rig. The test rig rotor is supported on two gas foil journal bearings manufactured at GRC, with all pertinent geometry disclosed. The resulting comparison shows that the rotordynamic coefficients calculated using XLGFBTH represent the dynamics of the system reasonably well, especially as they pertain to predicting critical speeds.

\section{SUBJECT TERMS}

Gas bearings; Foil bearings; Rotor dynamics

\begin{tabular}{|c|c|c|c|c|c|}
\hline \multicolumn{3}{|c|}{ 16. SECURITY CLASSIFICATION OF: } & \multirow{2}{*}{$\begin{array}{l}\text { 17. LIMITATION OF } \\
\text { ABSTRACT } \\
\text { UU }\end{array}$} & \multirow{2}{*}{$\begin{array}{l}\text { 18. NUMBER } \\
\text { OF } \\
\text { PAGES } \\
18\end{array}$} & \multirow{2}{*}{$\begin{array}{l}\text { 19a. NAME OF RESPONSIBLE PERSON } \\
\text { STI Help Desk (email:help@sti.nasa.gov) } \\
\text { 19b. TELEPHONE NUMBER (include area code) } \\
\text { 443-757-5802 }\end{array}$} \\
\hline $\begin{array}{l}\text { a. REPORT } \\
U\end{array}$ & $\begin{array}{l}\text { b. ABSTRACT } \\
U\end{array}$ & $\begin{array}{l}\text { c. THIS } \\
\text { PAGE } \\
\text { U }\end{array}$ & & & \\
\hline
\end{tabular}



